\title{
Possibility of paclitaxel as an alternative radiosensitizer to 5-fluorouracil for colon cancer
}

\author{
JUNICHIRO HIRO, YASUHIRO INOUE, YUJI TOIYAMA, SHIGEYUKI YOSHIYAMA, \\ KOJI TANAKA, YASUHIKO MOHRI, CHIKAO MIKI and MASATO KUSUNOKI

\begin{abstract}
Division of Reparative Medicine, Department of Gastrointestinal and Pediatric Surgery, Institute of Life Sciences, Mie University Graduate School of Medicine, 2-174 Edobashi, Tsu, Mie 514-8507, Japan
\end{abstract}

Received April 6, 2010; Accepted June 10, 2010

DOI: 10.3892/or_00000951

\begin{abstract}
To evaluate the feasibility of paclitaxel (PTX) radiosensitization for colon cancer, we investigated the cytotoxic and G2/M checkpoint protein (Chk1, Wee1, Bub1, MAD2) effects of 5-fluorouracil (5-FU) or PTX combined with radiation in the human colon cancer cell line LoVo. Cytotoxicity and radiocytotoxicity were evaluated for each drug by the WST- 8 colorimetric assay. The IC20 for each drug was determined as a cytotoxic concentration from a survival curve. LoVo cells were exposed to the IC20 of each drug for $24 \mathrm{~h}$ and then irradiated. Expressions of the G2/M checkpoint proteins were confirmed by Western blot analysis. Cytotoxicity was induced by 5-FU or PTX alone in a timeand dose-dependent manner. The IC20 of PTX caused higher radiosensitivity than the IC20 of $5-\mathrm{FU}(\mathrm{P}<0.05)$. Western blot analysis revealed different expression patterns of the G2/M checkpoint proteins between 5-FU and PTX pretreatments. 5-FU combined with radiation tended to decrease the expressions of all $\mathrm{G} 2 / \mathrm{M}$ checkpoint proteins in a timedependent manner. PTX combined with radiation maintained high expressions of Chk1 and MAD2 proteins for $24 \mathrm{~h}$ postradiation and, in particular, MAD2 protein was strongly induced by PTX with high-dose radiation. PTX showed higher radio-sensitization than 5-FU for the colon cancer cell line LoVo and may be an alternative radiosensitizer to 5-FU in the clinical setting.
\end{abstract}

\section{Introduction}

Chemoradiotherapy is now widely used as the definitive and adjuvant therapy for the majority of cancer patients. Randomized trials have shown that such combined treatments

Correspondence to: Dr Masato Kusunoki, Division of Reparative Medicine, Department of Gastrointestinal and Pediatric Surgery, Institute of Life Sciences, Mie University Graduate School of Medicine, 2-174 Edobashi, Tsu, Mie 514-8507, Japan

E-mail: kusunoki@clin.medic.mie-u.ac.jp

Key words: 5-fluorouracil, colon cancer, paclitaxel, radiosensitivity improve survival compared with radiation alone in locally advanced cancers of the head and neck, lung, esophagus, stomach and rectum (1-5). Despite these resounding clinical successes, the mechanisms by which conventional chemotherapeutic agents produce radiosensitization remain largely unknown. Recently, the interest in preoperative chemoradiotherapy for resectable rectal cancer has increased, because it has the advantage of enhancing local-regional control by eliminating microscopic residual disease around the primary tumor and in the draining lymphatics, with a possible positive impact on overall survival (5).

5-Fluorouracil (5-FU) is one of the most commonly used chemotherapeutic agents for colorectal cancer and has been extensively used with radiation. There are a number of mechanisms by which 5-FU could increase radiosensitivity at the cellular level. 5-FU-induced radiosensitivity is thought to be responsible for the killing of S phase cells, which are relatively radioresistant (6). However, this effect cannot account for all of the increase in radiosensitivity produced by the drug. Several studies have suggested that 5-FU should be given continuously during a course of fractionated radiation if radiosensitization is to be achieved (7-9).

On the other hand, paclitaxel (PTX) is known to be one of the most active cancer chemotherapeutic agents. It is effective against a variety of human tumors, including ovarian, breast, head and neck, and non-small cell lung cancers (10-13). Unlike 5-FU, PTX interferes with mitotic spindle function by enhancing the rate and yield of microtubule assembly and preventing microtubule depolymerization, resulting in $\mathrm{G} 2 / \mathrm{M}$ arrest (14). Since the G2/M phase is the most radiosensitive phase of the cell cycle, G2/M arrest induced by PTX provides a biological rationale for testing PTX/radiation combination treatments in vitro (15). Preliminary in vitro studies have suggested that PTX is a useful radiosensitizing agent in a variety of tumor cell lines $(16,17)$. Interestingly, PTX is even considered to be a radiosensitizer at low doses. However, in light of the controversial experimental data, the existence and extent of its effect at low doses is the subject of intense debate $(18,19)$. Although, clinical trials have unfortunately demonstrated that PTX as a single agent does not show activity in colorectal cancer (20), we were interested in the function of PTX as a cell cycle regulator and hypothesized that it may be an alternative radiosensitizer to 5-FU for colorectal cancer, especially in cases where the aim of the concurrent chemotherapy is enhancement of local control rather than systemic 
control. To confirm this hypothesis, we simultaneously evaluated the radiosensitizing mechanisms of 5-FU and PTX for colon cancer, from the viewpoint of cell cycle.

The present study aimed to investigate the cytotoxic and G2/M checkpoint protein effects of 5-FU or PTX combined with radiation in a human colon cancer cell line and to evaluate the feasibility of PTX radiosensitization for colon cancer.

\section{Materials and methods}

Cell culture. A wild-type p53-expressing human colon adenocarcinoma cell line, LoVo, was obtained from the Cell Resource Center for Biomedical Research (Institute of Development, Aging and Cancer, Tohoku University, Tokyo, Japan). LoVo cells were grown in RPMI-1640 (Sigma-Aldrich, St. Louis, MO, USA) supplemented with fetal bovine serum [10\% (v/v); Gibco BRL, Tokyo, Japan], glutamine (2 mM), penicillin $(100000 \mathrm{U} / \mathrm{l})$ and streptomycin $(100 \mathrm{mg} / \mathrm{l})$ at $37^{\circ} \mathrm{C}$ in a $5 \% \mathrm{CO}_{2}$ incubator.

Anticancer agents. 5-FU and PTX were obtained from SigmaAldrich, reconstituted in distilled water at appropriate concentrations and stored at $-20^{\circ} \mathrm{C}$ until use.

Experimental protocol. Although the IC20 (drug concentration responsible for $20 \%$ cell growth inhibition) of each drug was used for this study, we used clinical concentrations as much as possible. The 5-FU concentrations were chosen based on both our previous reports (21-23) and drug information obtained from Kyowa Hakko Kogyo (Tokyo, Japan). The drug information for 5-FU indicated that its plasma concentrations reach $15.3 \mu \mathrm{g} / \mathrm{ml}(100 \mu \mathrm{M})$ after a bolus injection of 5 -FU $\left(500 \mathrm{mg} / \mathrm{m}^{2}\right)$ and $0.6 \mu \mathrm{g} / \mathrm{ml}(5 \mu \mathrm{M})$ during continuous infusion of $5-\mathrm{FU}(60 \mathrm{mg} / \mathrm{kg} / 48 \mathrm{~h})$. The PTX concentrations were chosen based on the plasma concentrations obtained from clinical use cited in the drug information for PTX (Taxol; Bristol Myers Squibb, Tokyo, Japan). This information indicated that the plasma concentrations of PTX reach $1-10 \mu \mathrm{g} / \mathrm{ml}(1-10 \mu \mathrm{M})$ after an injection and 0.05-0.1 $\mu \mathrm{g} / \mathrm{ml}$ $(50-100 \mathrm{nM})$ at $24 \mathrm{~h}$ after drip infusion of PTX $(105-270 \mathrm{mg} /$ $\mathrm{m}^{2}$ ). To elucidate the irradiation effects in detail, irradiation was carried out at different doses (2.5 and 5 Gy). All irradiation treatments were performed with a CLINAC 2100C X-ray system (Varian Oncology Services, USA) at $4 \mathrm{MV}$, using a 40-mm solid water phantom and a dose rate of $217 \mathrm{cGy} / \mathrm{min}$.

Drug concentrations, irradiation and administration schedules. As mentioned above, we adopted clinically relevant concentrations of 5-FU and PTX in this study. Although we should ideally have considered the doubling time of LoVo cells before deciding the exposure time, we chose to use an exposure of $24 \mathrm{~h}$ for each drug for experimental simplicity. The final concentrations ranged from $0.1-1000 \mu \mathrm{M}$ for 5-FU and $0.001-10 \mu \mathrm{M}$ for PTX. The drug exposure and irradiation schedules are summarized in Fig. 1. To test the cytotoxicity of each drug, LoVo cells in the exponential growth phase were treated with various concentrations of 5-FU or PTX for $24 \mathrm{~h}$. After discarding the medium containing each drug and replacing it with fresh medium, the cytotoxicity was evaluated using a 2-(2-methoxy-4-nitrophenyl)-3-(4-

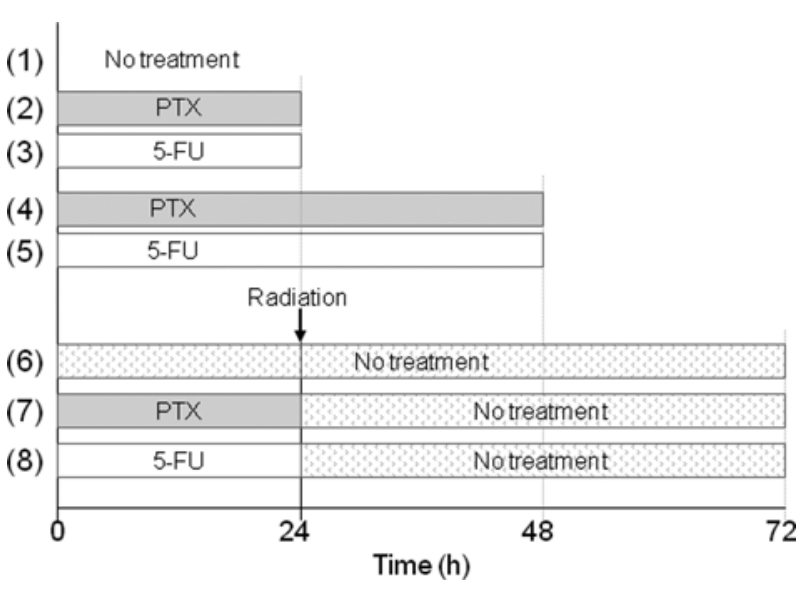

Figure 1. Drug administration and irradiation schedules used in this study. (1) No treatment, comprising control cells. (2) and (3) drug exposure for $24 \mathrm{~h}$. (4) and (5) drug exposure for $48 \mathrm{~h}$. (6) No drug treatment or irradiation, comprising radiation control cells. (7) and (8) irradiation after $24 \mathrm{~h}$ of drug exposure (medium replaced with fresh medium).

nitrophenyl)-5-(2,4-disulfophenyl)-2H-tetrazolium, monosodium salt (WST-8) colorimetric assay. For irradiation experiments, LoVo cells were treated with each drug at its IC20 for $24 \mathrm{~h}$. After removing the drugs from the wells and refilling the wells with fresh medium, irradiation was carried out at different doses. The irradiated cells were incubated for 0,24 or $48 \mathrm{~h}$, and the cytotoxicity was evaluated using the WST-8 colorimetric assay.

Growth inhibition assay. Cytotoxicity was evaluated by the WST-8 colorimetric assay using a Cell Counting kit (Dojindo Laboratories, Tokyo, Japan) according to the manufacturer's instructions. Cells $\left(5 \times 10^{3}\right)$ were seeded into 96-well plates (Becton-Dickinson Labware, Franklin Lakes, NJ, USA) in $100 \mu \mathrm{l}$ of culture medium for $24 \mathrm{~h}$ prior to drug exposure, and then treated with various concentrations of 5-FU or PTX for various durations. Cell viability was determined colorimetrically by the optical density at a wavelength of $450 \mathrm{~nm}$ using a microplate reader (SoftMax; Molecular Devices, Sunnyvale, CA, USA). The percent cell survival for each drug concentration was calculated using the following formula: (absorbance of test wells/absorbance of control wells) x 100.

Western blot analysis. At 0, 12, 24, 36 and $48 \mathrm{~h}$ after irradiation, cells were harvested and subjected to immunoblotting analysis. The cells were homogenized in lysis buffer (Trisbuffered saline, $\mathrm{pH} 7.5$, containing $2 \%$ Triton X-100) for $5 \mathrm{~min}$ on ice. The protein concentration was measured by the BCA protein assay (Pierce, Rockford, IL, USA). Lysates containing $20 \mu \mathrm{g}$ of total protein were mixed with an equal volume of $2 \mathrm{X}$ Laemmli loading buffer containing 2-mercaptoethanol and heated at $100^{\circ} \mathrm{C}$ for $5 \mathrm{~min}$. The samples were electrophoretically separated in $12.5 \%$ gradient polyacrylamide gels containing $0.1 \%$ SDS at $25 \mathrm{~mA}$ for $2 \mathrm{~h}$, followed by semi-dry transfer to Immun-Blot PVDF membranes (Bio-Rad Laboratories, Hercules, CA, USA) at $12 \mathrm{~V}$ for $2 \mathrm{~h}$. The membranes were blocked with $2 \%$ skimmed milk in Tris-buffered saline ( $\mathrm{pH} 7.5$ ) containing $0.1 \%$ Tween-20. The primary antibodies 

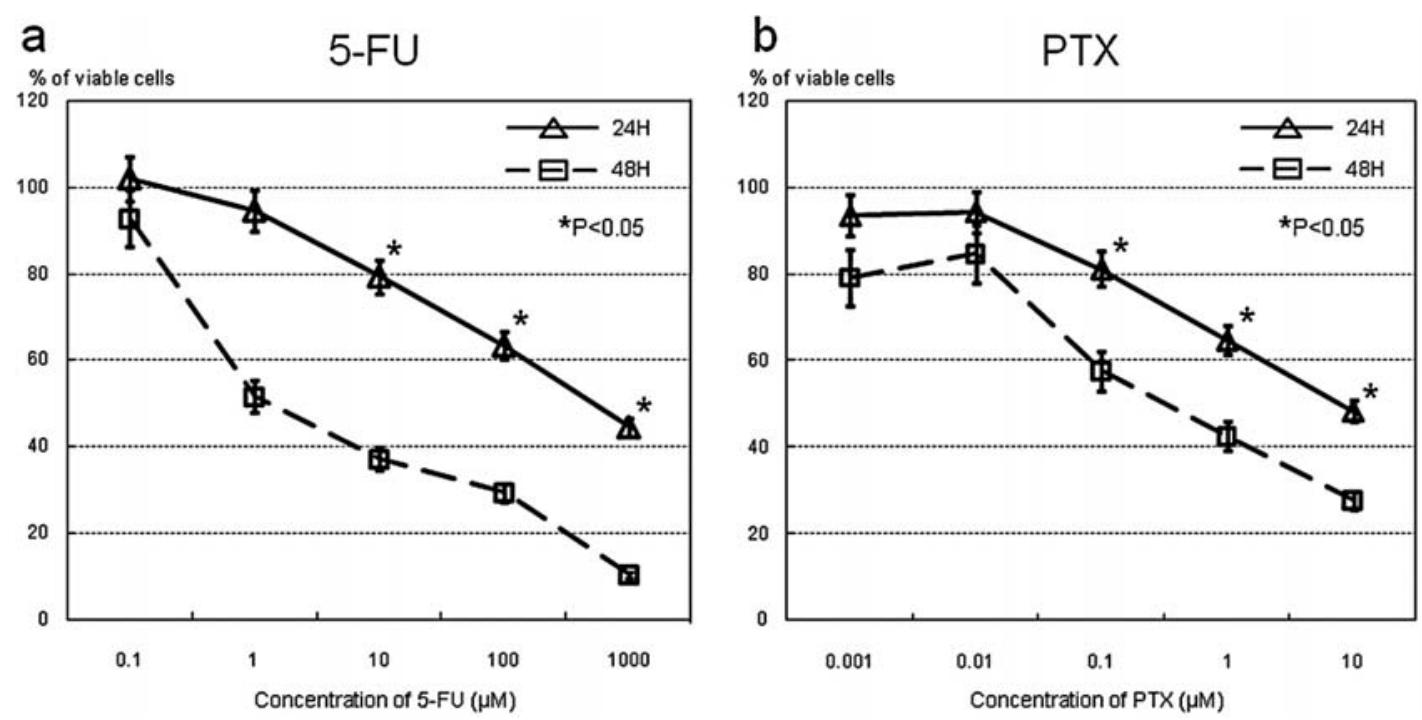

Figure 2. Cytotoxicities of 5-FU and PTX toward LoVo cells. Cells were treated with different concentrations of 5-FU (A) and PTX (B) for 24 (triangles) or $48 \mathrm{~h}$ (squares). Cell growth was determined using a WST-8 colorimetric assay. The results are expressed as the percentage of cell growth relative to untreated control cells. The data represent the means \pm SD of three experiments.

used were: mouse monoclonal anti-hsMAD2 (1:1000 dilution; Transduction Laboratories, Lexington, KY, USA); mouse monoclonal anti-Wee1 (1:400 dilution; Santa Cruz Biotechnology, Santa Cruz, CA, USA); mouse monoclonal antiChk1 (1:400 dilution; Santa Cruz Biotechnology); mouse monoclonal anti-Bub1 (1:400 dilution; Chemicon International, Temecula, CA, USA); and mouse monoclonal anti-actin (clone C4; 1:3000 dilution; ICN Biomedicals, Aurora, OH, USA). The secondary antibody used was alkaline phosphataseconjugated goat anti-mouse IgG (Promega, Madison, WI, USA) diluted 1:1000. Following treatment with an enhanced chemiluminescence detection solution, the membranes were exposed to X-ray film for autoradiographic visualization. The films were scanned and the relative quantities of the protein bands were analyzed by densitometry using CS Analyzer version 2.0 (ATTO Corp., Tokyo, Japan).

Statistical analysis. The results are expressed as means \pm SD. The Mann-Whitney U test was used for comparisons between unpaired groups. Values of $\mathrm{P}<0.05$ were considered statistically significant. Stat View analysis software (version 5; Abacus Concepts, Inc., Berkeley, CA) was used for all analysis.

\section{Results}

Cytotoxic effects of 5-FU and PTX. Growth-inhibitory effects were observed for treatment with either 5-FU or PTX alone in a time- and dose-dependent manner (Fig. 2). LoVo cell growth was inhibited at the clinically used concentrations of 5-FU (0.1-10 $\mu \mathrm{M})$ and PTX $(0.001-10 \mu \mathrm{M})$. The IC20 values for 5-FU and PTX were 10 and $0.1 \mu \mathrm{M}$, respectively.

Radiocytotoxic effects of 5-FU and PTX. To examine whether 5 -FU or PTX can target LoVo cells and confer radiosensitivity, cells were treated with the IC20 values of 5-FU $(10 \mu \mathrm{M})$ or PTX $(0.1 \mu \mathrm{M})$ for $24 \mathrm{~h}$. After removing the drugs, the cells were irradiated at a dose of 2.5 or 5 Gy. Growth inhibition was measured using the WST- 8 colorimetric assay. The results are shown in Fig. 3. In all groups, radiocytotoxic effects were seen in a time- and radiation dose-dependent manner. PTX pretreatment was found to have the highest radiosensitivity enhancement effect for both radiation doses. Fig. 3a shows the radiosensitivity effects of 5-FU and PTX with low-dose radiation (2.5 Gy). PTX pretreatment caused a higher radiosensitivity enhancement effect than 5-FU for $48 \mathrm{~h}$ after individual pretreatment $(\mathrm{P}<0.05)$. Interestingly, PTX, but not $5-\mathrm{FU}$, showed a radiosensitivity enhancement effect at $24 \mathrm{~h}$ after pretreatment. Fig. 3b shows the radiosensitivity effects of 5-FU and PTX with high-dose radiation (5 Gy). The maximum effect was seen when $0.1 \mu \mathrm{M}$ PTX was combined with 5 Gy of irradiation. PTX pretreatment showed a higher radiocytotoxic effect than 5-FU pretreatment and radiation alone at both 24 and $48 \mathrm{~h}$ after pretreatment $(\mathrm{P}<0.05)$. We subsequently investigated the relationships of these radiosensitizing effects with cell cycle protein expressions.

Western blot analysis. The results of Western blot analysis are shown in Fig. 4. Radiation alone at 2.5 or 5 Gy showed similar expression patterns of G2/M-related proteins (Fig. 4a). The expressions of the Chk 1 and Wee 1 proteins in the control cells treated with radiation alone increased until $24 \mathrm{~h}$ after irradiation and then returned to their basal levels. Bub1 protein expression was decreased in a time-dependent manner by irradiation at $2.5 \mathrm{~Gy}$, but was not affected by irradiation at 5 Gy. MAD2 protein expression gradually increased until $24 \mathrm{~h}$ after 2.5-Gy irradiation and $36 \mathrm{~h}$ after 5-Gy irradiation.

After PTX or 5-FU pretreatment, we observed wide differences in the expressions of some proteins (Fig. 4b, c). 5-FU pretreatment tended to decrease the expressions of all $\mathrm{G} 2 / \mathrm{M}$ checkpoint proteins in a time-dependent manner. In contrast, PTX pretreatment maintained Chk1 and MAD2 protein expressions at high levels for $24 \mathrm{~h}$ post-irradiation and, in particular, MAD2 protein expression was strongly induced by $5-$ Gy radiation when the maximum radiocytotoxic effect 

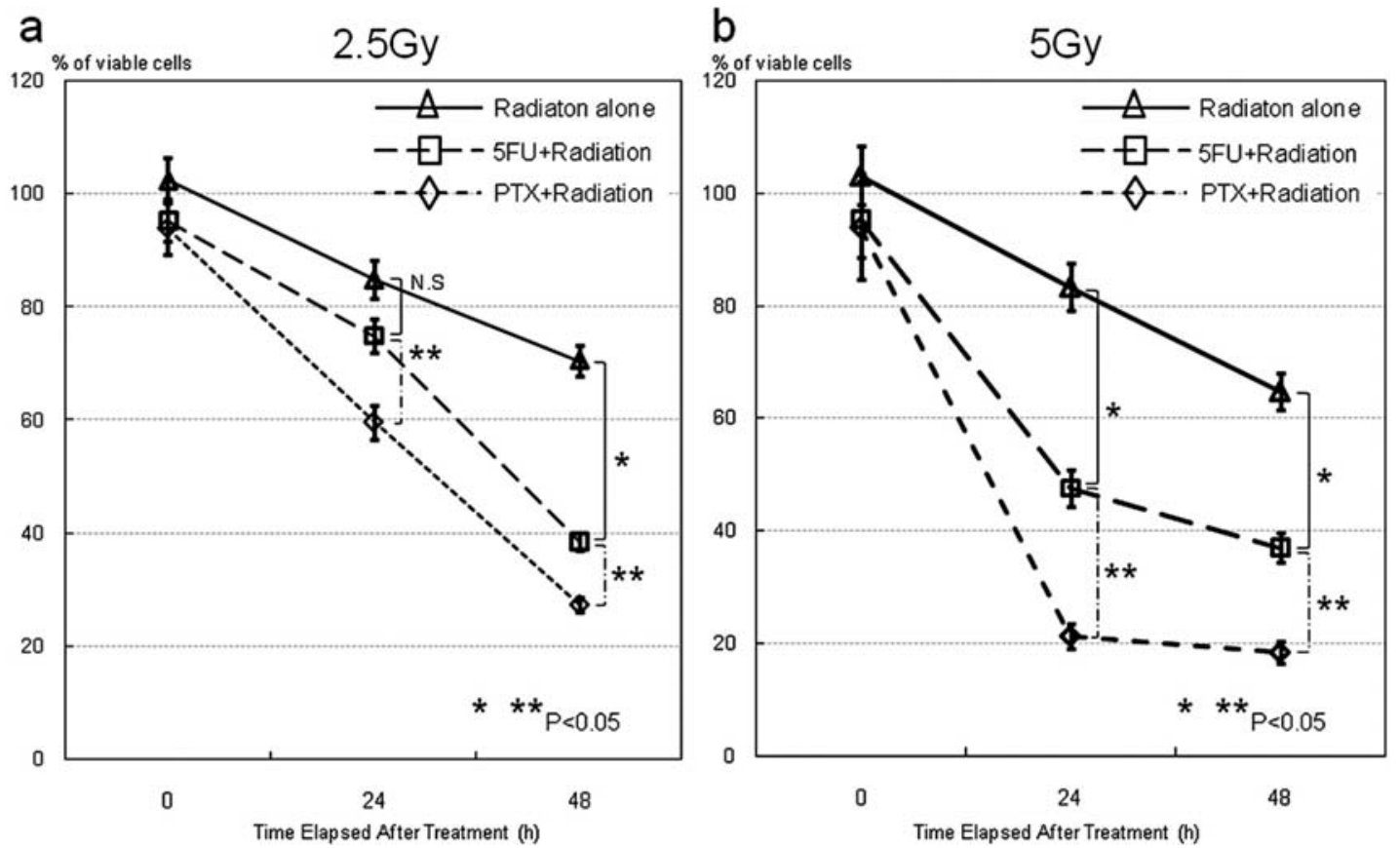

Figure 3. Radiocytotoxic effects of 5-FU and PTX on LoVo cells. (A), (B) LoVo cells were pretreated with 5-FU (squares) or PTX (diamonds) at their IC20 values for $24 \mathrm{~h}$ and then irradiated with 2.5 (A) or 5 (B) Gy. Other cells were treated with radiation alone (triangles). Cell growth was determined using a WST-8 colorimetric assay. The results are expressed as the percentage of cell growth relative to untreated control LoVo cells. The data represent the means \pm SD of three experiments.

a
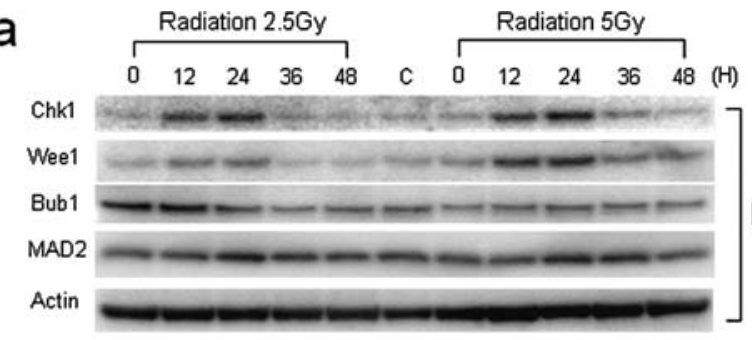

Radiation alone
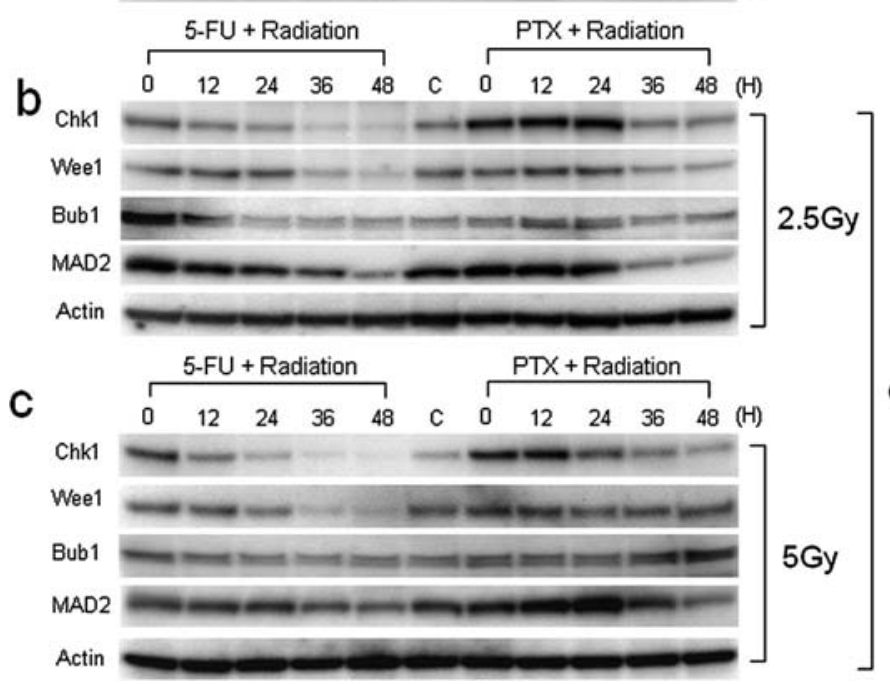

\section{Chemoradiation}

$5 G y$

Figure 4. Western blot analyses of Chk1, Wee1, Bub1, MAD2 and actin in LoVo cells. (A) Cells treated with radiation alone (2.5 or 5 Gy). (B) Cells treated with $2.5 \mathrm{~Gy}$ of irradiation after pretreatment for $24 \mathrm{~h}$ with 5-FU or PTX at their IC20 values. (C) Cells treated with 5 Gy of irradiation after pretreatment for $24 \mathrm{~h}$ with 5-FU or PTX at their IC20 values.

was obtained. Furthermore, at $24 \mathrm{~h}$ after 2.5 -Gy irradiation, which showed radiosensitization enhancement by PTX but not 5-FU, PTX pretreatment clearly induced Chk1 and Bub1 protein expressions, unlike 5-FU.

\section{Discussion}

In general, cells are most sensitive to irradiation during mitosis in the $\mathrm{G} 2$ phase, less sensitive in the G1 phase and least sensi- 
tive during the latter part of the S phase (24). Since various types of chemotherapeutic agents are able to arrest cells at specific cell-cycle checkpoints, previous studies have explored the use of different chemotherapeutic agents to synchronize and arrest cells in the radiosensitive phases of the cell cycle $(25,26)$. 5-FU is an analog of uracil, which is converted intracellularly into metabolites that inhibit the enzyme thymidylate synthase, thereby preventing DNA, RNA and protein synthesis $(6,7)$. 5-FU has been the most commonly used chemotherapeutic agent in the clinical treatment of colorectal cancer. Radiosensitization by 5-FU is thought to increase radiosensitivity at the cellar level by killing cells in the $\mathrm{S}$ phase, which are relatively radioresistant (6). However, 5-FU-induced radiosensitization cannot be completely explained by redistribution of the cells into a radiosensitive phase of the cell cycle. The mechanism of 5-FU-induced radiosensitization remains largely unknown at the cellular level. Meanwhile, PTX is characterized by specific inhibition of microtubule depolymerization, thereby causing $\mathrm{G} 2 / \mathrm{M}$ phase accumulation and mitotic arrest of tumor cells $(27,28)$. In vitro, PTX has the exceptional property of causing cancer cell death independently of wild-type p53. PTX-mediated blockade at the G2/M phase can activate cell-cycle control pathways to induce apoptosis independently of p53 $(29,30)$. PTX also enhances the cytotoxic effects of ionizing radiation on pancreatic, breast, ovarian, and head and neck cancer cell lines, possibly by inducing arrest at the G2 and mitotic phases of the cell cycle, which are the most radiosensitive $(16,17,31,32)$. However, the Eastern Cooperative Oncology Group trial demonstrated that PTX as a single agent does not have activity against colon or rectum adenocarcinoma (20). Therefore, in colorectal cancer treatment, PTX is rarely used and has not been sufficiently evaluated.

In the present study, we investigated the biological effects of optimal 5-FU or PTX treatment and irradiation on the human LoVo colon cancer cell line. The drug concentrations used were calculated according to those used in clinical situations. To simulate a clinical setting, we used the IC20 of each drug as the minimum cytotoxic concentration and examined their effects in combination with 2.5 and 5 Gy of irradiation. In addition, we investigated the expression patterns of major G2/M-related proteins (Chk1, Wee1, Bub1 and MAD2). Chk1 is thought to play a central role in G2 phase arrest $(33,34)$. Entry into mitosis requires activation of $\mathrm{Cdc} 2$ following removal of inhibitory phosphates by $\mathrm{Cdc} 25$. Cdc2 kinase activity is regulated in an opposing manner by the kinase Wee-1 $(35,36)$. MAD2 and Bub1 play central roles in the mitotic checkpoint and induce $\mathrm{G} 2 / \mathrm{M}$ phase arrest. Bub1 is involved in recruiting other checkpoint proteins to unattached kinetochores, which subsequently activate MAD2, leading to suppression of anaphase-promoting complex formation and halting entry into anaphase $(29,30)$.

Our present results revealed that PTX pretreatment had a significantly higher radiosensitizing effect than 5-FU at both the doses of radiation examined. Previous studies involving flow cytometric analyses of LoVo cells demonstrated that $24 \mathrm{~h}$ of exposure to $10 \mu \mathrm{M} 5$-FU increases the number of $\mathrm{S}$-phase cells among the treated cells compared with control cells, while $24 \mathrm{~h}$ of exposure to $0.1 \mu \mathrm{M}$ PTX induces accumulation of tumor cells in the G2/M phase $(18,37)$. These findings suggest that high radiosensitivity may be derived from radiation exposure under the presence of $\mathrm{G} 2 / \mathrm{M}$ phaseaccumulated cells induced by PTX. The present study also revealed that the expression patterns of G2/M-related proteins following treatment with PTX and radiation differed significantly from those of 5-FU and radiation, and that these effects were especially dependent on the radiation dose. The combination of PTX and low-dose radiation may result in a large and prolonged blockade of the G2/M cell cycle phase and the cancer cells may become arrested at the G2/M checkpoint to repair radiation-induced DNA damage. Furthermore, MAD2 protein expression was strongly induced by 5 Gy of irradiation when the maximum radiocytotoxic effect was obtained. This observation suggests that the combination of PTX and high-dose radiation may induce mitotic catastrophe, since several studies have demonstrated the occurrence of PTXinduced mitotic cell cycle arrest or MAD2 protein expression $(29,30,38,39)$.

In conclusion, low-dose PTX showed higher radiosensitization than 5-FU for LoVo colon cancer cell line cells. PTX may have potential as an alternative radiosensitizing agent to 5-FU for colon cancer, although prospective clinical trials are needed to determine the actual benefits.

\section{References}

1. Bernier J, Cooper JS, Pajak TF, et al: Defining risk levels in locally advanced head and neck cancers: a comparative analysis of concurrent postoperative radiation plus chemotherapy trials of the EORTC (\#22931) and RTOG (\#9501). Head Neck 27: 843-850, 2005.

2. Pignon JP, Arriagada R, Ihde DC, et al: A meta-analysis of thoracic radiotherapy for small cell lung cancer. N Engl J Med 327: 1618-1624, 1992.

3. Herskovic A, Martz K, Al-Sarraf M, et al : Combined chemotherapy and radiotherapy compared with radiotherapy alone in patients with cancer of the esophagus. N Engl J Med 326: 1593-1598, 1992.

4. Bleiberg H, Goffin JC, Dalesio O, et al: Adjuvant radiotherapy and chemotherapy in respectable gastric cancer: a randomised trial of the gastrointestinal tract cancer co-operative group of the EORTC. Eur J Surg Oncol 15: 535-543, 1989.

5. Colorectal Cancer Collaborative Group: Adjuvant radiotherapy for rectal cancer: a systematic overview of 8507 patients from 22 randomised trials. Lancet 358: 1291-1304, 2001.

6. Davis MA, Tang HY, Maybaum J and Lawrence TS: Dependence of fluorodeoxyuridine-mediated radiosensitization on $\mathrm{S}$ phase progression. Int J Radiat Biol 67: 509-517, 1995.

7. Miller EM and Kinsella TJ: Radiosensitization by fluorodeoxyuridine: effects of thymidylate synthase inhibition and cell synchronization. Cancer Res 52: 1687-1694, 1992.

8. Rich TA, Shepard RC and Mosley ST: Four decades of continuing innovation with fluorouracil: current and future approaches to fluorouracil chemoradiation therapy. J Clin Oncol 22: 2214-2232, 2004.

9. Mohiuddin M, Winter K, Mitchell E, et al: Randomized phase II study of neoadjuvant combined-modality chemoradiation for distal rectal cancer: Radiation Therapy Oncology Group Trial 0012. J Clin Oncol 24: 650-655, 2006.

10. Parmar MK, Ledermann JA, Colombo N, et al: Paclitaxel plus platinum-based chemotherapy versus conventional platinumbased chemotherapy in women with relapsed ovarian cancer: the ICON4/AGO-OVAR-2.2 trial. Lancet 361: 2099-2106, 2003.

11. Kümmel S, Krocker J, Kohls A, et al: Randomised trial: survival benefit and safety of adjuvant dose-dense chemotherapy for node-positive breast cancer. Br J Cancer 94: 1237-1244, 2006.

12. Moore DH, Blessing JA and McQuellon RP: Phase III study of cisplatin with or without paclitaxel in stage IVB, recurrent, or persistent squamous cell carcinoma of the cervix: a Gynecologic Oncology Group study. J Clin Oncol 22: 3113-3119, 2004. 
13. Chu Q, Vincent M, Logan D, Mackay JA and Evans WK Taxanes as first-line therapy for advanced non-small cell lung cancer: a systematic review and practice guideline. Lung Cancer 50: 355-374, 2005

14. Schiff PB and Horwitz SB: Taxol stabilizes microtubules in mouse fibroblast cells. Proc Natl Acad Sci USA 77: 1561-1565, 1980.

15. Choy H, Rodriguez FF, Koester S, Hilsenbeck S and von Hoff DD: Investigation of taxol as a potential radiation sensitizer. Cancer 71: 3774-3778, 1993.

16. Leonard CE, Chan DC, Chou TC, Kumar R and Bunn PA: Paclitaxel enhances in vitro radiosensitivity of squamous carcinoma cell lines of the head and neck. Cancer Res 56: 5198-5204, 1996.

17. Rodriguez M, Sevin BU, Perras J, et al: Paclitaxel: a radiation sensitizer of human cervical cancer cells. Gynecol Oncol 57: 165-169, 1995.

18. Niero A, Emiliani E, Monti G, et al: Paclitaxel and radiotherapy: sequence-dependent efficacy - a preclinical model. Clin Cancer Res 5: 2213-2222, 1999.

19. Lövey J, Fazekas K, Ladányi A, Németh G and Tímár J: Lowdose irradiation and short-exposure suboptimal-dose paclitaxel adversely modulate metastatic potential of squamous carcinoma cells. Strahlenther Onkol 179: 812-818, 2003.

20. Einzig AI, Neuberg D, Wiernik PH, et al: Phase II trial of paclitaxel in patients with advanced colon cancer previously untreated with cytotoxic chemotherapy: an Eastern Cooperative Oncology Group Trial (PA286). Am J Ther 3: 750-754, 1996.

21. Kusunoki M, Yanagi $\mathrm{H}$, Kotera $\mathrm{H}$, Noda $\mathrm{M}$ and Yamamura $\mathrm{T}$ : Effects of pharmacokinetic modulating chemotherapy using oral UFT and continuous venous 5FU infusion on the prognosis of irradiated rectal carcinomas with p53 overexpression. Int J Oncol 13: 653-657, 1998

22. Kusunoki M, Yanagi H, Noda M, Yoshikawa R and Yamamura T: Results of pharmacokinetic modulating chemotherapy in combination with hepatic arterial 5-fluorouracil infusion and oral UFT after resection of hepatic colorectal metastases. Cancer 89: 1228-1235, 2000.

23. Yoshikawa R, Kusunoki M, Yanagi H, et al: Dual antitumor effects of 5-fluorouracil on the cell cycle in colorectal carcinoma cells: a novel target mechanism concept for pharmacokinetic modulating chemotherapy. Cancer Res 61: 1029-1037, 2001.

24. Sinclair W: Cyclic X-ray responses in mammalian cells in vitro. Radiat Res 33: 620-643, 1968.

25. Price LA and Hill BT: A kinetically based logical approach to the chemotherapy of head and neck cancer. Clin Otolaryngol 2: 339-345, 1977.
26. Minarik L and Hall EJ: Taxol in combination with acute and low dose rate irradiation. Radiother Oncol 32: 124-128, 1994.

27. Wani MC, Taylor HL, Wall ME, Coggon P and McPhail AT: Plant antitumor agents. VI. The isolation and structure of taxol, a novel antileukemic and antitumor agent from Taxus brevifolia. J Am Chem Soc 93: 2325-2327, 1971.

28. Rowinsky EK, Donehower RC, Jones RJ and Tuker RW: Microtubule changes and cytotoxicity in leukemic cell lines treated with taxol. Cancer Res 48: 4093-4100, 1998.

29. O'Connor PM, Jackman J, Bae I, et al: Characterization of the p53 tumor suppressor pathway in cell lines of the National Cancer Institute anticancer drug screen and correlations with the growthinhibitory potency of 123 anticancer agents. Cancer Res 57: 4285-4300, 1997.

30. Wahl AF, Donaldson KL, Fairchild C, et al: Loss of normal p53 function confers sensitization to Taxol by increasing G2/M arrest and apoptosis. Nat Med 2: 72-79, 1996.

31. Liebmann J, Cook JA, Fisher J, Teague D and Mitchell JB: In vitro studies of Taxol as a radiation sensitizer in human tumor cells. J Natl Cancer Inst 86: 441-446, 1994.

32. Liebmann J, Cook JA, Fisher J, Teague D and Mitchell JB: Changes in radiation survival curve parameters in human tumor and rodent cells exposed to paclitaxel (Taxol). Int J Radiat Oncol Biol Phys 29: 559-564, 1994.

33. Liu Q, Guntuku S, Cui XS, et al: Chk1 is an essential kinase that is regulated by Atr and required for the G(2)/M DNA damage checkpoint. Genes Dev 14: 1448-1459, 2000.

34. Sanchez Y, Bachant J, Wang H, et al: Control of the DNA damage checkpoint by chk1 and rad53 protein kinases through distinct mechanisms. Science 286: 1166-1171, 1999.

35. Lee J, Kumagai A and Dunphy WG: Positive regulation of Wee1 by Chk1 and 14-3-3 proteins. Mol Biol Cell 12: 551-563, 2001.

36. McGowan $\mathrm{CH}$ and Russell P: Cell cycle regulation of human Wee1. EMBO J 14: 2166-2175, 1995.

37. Inoue $\mathrm{Y}$, Tanaka $\mathrm{K}$, Hiro J, et al: In vitro synergistic antitumor activity of a combination of 5-fluorouracil and irinotecan in human colon cancer. Int J Oncol 28: 479-486, 2006.

38. Huang TS, Shu CH, Chao Y, Chen SN and Chen LL: Activation of MAD 2 checkprotein and persistence of cyclin B1/CDC 2 activity associate with paclitaxel-induced apoptosis in human nasopharyngeal carcinoma cells. Apoptosis 5: 235-241, 2000.

39. Sudo T, Nitta M, Saya H and Ueno NT: Dependence of paclitaxel sensitivity on a functional spindle assembly checkpoint. Cancer Res 64: 2502-2508, 2004. 